\title{
Diplodomica I. Chemical Composition of Repugnatorial Secretions of Cuban Endemic Millipede gen. Rhinocricus sp. ${ }^{\dagger}$
}

\author{
Juan Enrique Tacoronte Morales ${ }^{1, *}$ and María Teresa Cabrera Pedroso ${ }^{2}$ \\ 1 Faculty of Science \& Technology, Technical University of Esmeraldas, PC 080150 Esmeraldas, Ecuador \\ 2 Faculty of Health Sciences, Universidad de Las Américas, UDLA, UDLA-Park, PC 170124 Quito, Ecuador; \\ maria.cabrera@udla.edu.ec \\ * Correspondence: jetacoronte@yahoo.com; Tel.: +593-991702915 \\ + Presented at the 23rd International Electronic Conference on Synthetic Organic Chemistry, 15 November- \\ 15 December 2019; Available online: https://ecsoc-23.sciforum.net/.
}

Published: 14 November 2019

\begin{abstract}
The composition of the repugnatorial secretion of some populations of the Cuban endemic millipede Rhinocricus inhabiting in the western region of the Cuban archipelago has been developed. Several quinonoids metabolites were identified. From some individuals (males), collected in forest and karst regions, $850 \mu \mathrm{g}$ of a deep brown-red secretion were obtained, and directly introduced into analytical instrumental (GC-MS and FTIR). The analysis of FTIR and GCMS spectra shows that major components of secretions are substituted hydroquinones, 1,4benzoquinones and aldehydes. The biological effects of these defensive secretions were evaluated on pathogenic microorganisms, showing interesting antimicrobial action. The ecological and evolutionary significance of chemical differentiation in millipedes populations require further study.
\end{abstract}

Keywords: millipede; defensive secretion; chemical composition; quinonoids; antimicrobial; chemical ecology

\section{Introduction}

Advances in the chemistry of natural products isolated from terrestrial invertebrate and their chemical ecology, via metabolomics and chemogenomics, offer new opportunities for bioprospecting of biodiversity in searching for new molecular entities with potential bioactivity and industrial applications, starting from minimum quantities of biological material including defensive secretions against predators or any ecological disturbance. The biodiversity of the (edaphic) fauna of terrestrial invertebrates of the Cuban archipelago has not been properly chemo-prospected; the efforts, presented here, are oriented to the isolation, structural elucidation, molecular mapping and strategic development of leading molecular systems based on secondary metabolites that would constitute a new potential pharmacological, agrochemical and structural entities (NPE + NAE + NSE). There are no reports detailing chemical ecology, biological activity and structural-compositional aspects of defensive secretions of Millipedes inhabiting in different eco-geographical regions of Cuban tropical archipelago [1-3]. The reported results constitute the first chemical analysis of repugnatorial ejections isolated and collected from individuals of some populations of the Cuban endemic millipede gen. Rhinocricus sp., inhabiting in the wester zone of the Cuban neotropical archipelago. Their microbiocidal action vs. microbial pathogens is reported. 


\section{Materials and Methods}

All reagents used were supplied by MERCK, Darmstadt, Germany, and were used without prior purification.

\subsection{IR Spectroscopy}

The infrared spectra were recorded on a PHILIPS ANALYTICAL FTIR PU-9600 spectrophotometer, Germany; the samples were prepared in potassium bromide $(\mathrm{KBr})$ tablets at $25^{\circ} \mathrm{C}$. Alternatively, the spectra were recorded in a JASCO-Canvas 4600, Japan system in CsBr tablets at $25^{\circ} \mathrm{C}$.

\subsection{NMR Spectroscopy}

NMR spectra were recorded on a BRUKER AC-250 instrument, Germany, at $25{ }^{\circ} \mathrm{C}$. The protonic chemical $(\delta)$ shifts are given in ppm, using tetramethylsilane as internal reference (TMS, $\delta=0.0$ ) and as a solvent $\mathrm{CDCl} 3$. The chemical shifts $(\delta)$ for $13 \mathrm{C}$ refer to the central peak of the $\mathrm{CDCl} 3$ solvent at $77.03 \mathrm{ppm}$.

\subsection{Gas Chromatography Coupled to Mass Spectrometry (GC-MS)}

A Hewlett-Packard 6890 gas chromatograph (Palo Alto, CA, USA) with 5973 quadrupole detection system (GC-MS) was used. The separations were carried out through a capillary column of Ultra 2 type (J \& W Scientific, Folsom, CA, USA), $12 \mathrm{~m}$ long and $0.22 \mathrm{~mm}$ of internal diameter. As carrier gas was used He at a flow of $1 \mathrm{~mL} / \mathrm{min}$. Temperature ramp: $60^{\circ} \mathrm{C}$ with increments of $10^{\circ} \mathrm{C} / \mathrm{min}$ up to $300^{\circ} \mathrm{C}$ (isothermal $5 \mathrm{~min}$.). Run time $30 \mathrm{~min}$. Injection volume $2 \mu \mathrm{L}$ at a temperature of $280^{\circ} \mathrm{C}$, in split mode (1:10 ratio). The ionization source was IE at $70 \mathrm{eV}$ operating at $230^{\circ} \mathrm{C}$. Acquisition mode: Full Scan. Range of m/e 40-700.

The following databases were used for structural characterization: Nist98 (National Institute of Standards and Technology, USA), PMW_TOX2 (Wiley Library and Pfleger Maurer Weber (PMW), National Metrology Institute of Japan (NMIJ); and National Institute of Advanced Industrial Science and Technology (AIST). Also, the databases where the chemical composition of the invertebrate defensive secretions (www.pherobase.com), and their GC-MS (Libraries for the rapid identification of metabolites in complex biological samples, Max-Planck Institute of Plant Molecular Physiology, Germany) are reported were considered. Using the reported sources and m/e data from the GC-MS, the most likely structures and their fragmentation mechanisms are postulated.

\subsection{Biological Material}

Adult individuals (males) of the millipede species gen. Rhinocricus sp. (Diplopoda, order Spirobolida, fam, Rhinocricidae) were collected in the following sites (6, forest and karst regions): Yumurí Valley (Matanzas), Banao (Sancti Spíritus), La Coca ( Habana, Florido Field: 82008'14" W; 230 09'22" N), Isla de La Juventud (820 49'14" W; 210 52'18" N), La Palma (Pinar del Río: 830 33'15" W; 220 45'24" N), Cuevas de Alamar (Habana) during the months of May-July 2015, 2016, 2017 and 2018. The specimens were kept in the Edaphic Fauna Laboratory of the Faculty of Biology, University of La Havana, Cuba and in the Organic Chemistry Laboratory of the Faculty of Science \& Technology at Technical University of Esmeraldas, Ecuador (voucher 001-003).

\subsection{Extraction and Isolation}

To obtain the defensive secretions (ejected by the ozopores located in the dorso-lateral part of the millipede's body) of intense reddish-brown coloration, the male individuals are stimulated by gently pressure. The secretion $(650-800 \mu \mathrm{g}$ /individual) is absorbed on Whatman 40 filter paper and cooled to $-10{ }^{\circ} \mathrm{C}$ The filter paper is extacted with diethyl ether $(5 \times 2 \mathrm{~mL})$ and the ether extracts are concentrated with $\mathrm{N} 2$ flow $(\mathrm{g})$ to dryness and stored at $-10{ }^{\circ} \mathrm{C}$ in $1 \mathrm{~mL}$ Eppendorf vials, and sealed with parafilm for further analysis. To each vial, with the dry extract, dichloromethane $(1 \mathrm{~mL})$ is 
added, the mixture is stirred, filtered through $0.45 \mu \mathrm{m}$ frit, and injected into the GC-MS $(2-20 \mu \mathrm{L})$. The collection of the secretion is depicted in Figure 1a,b.

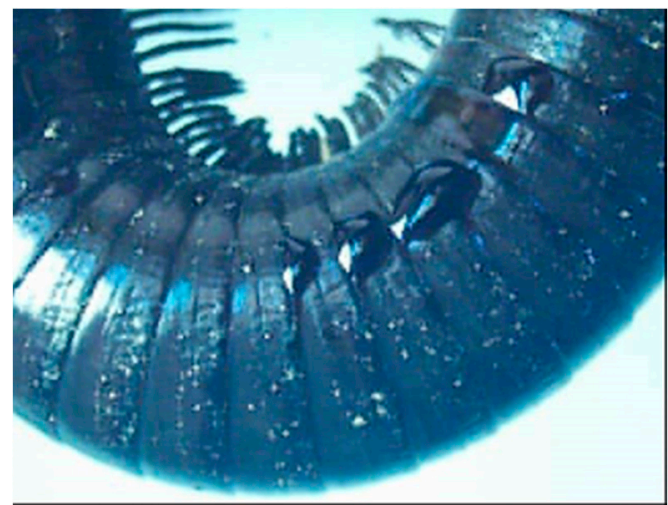

(a)

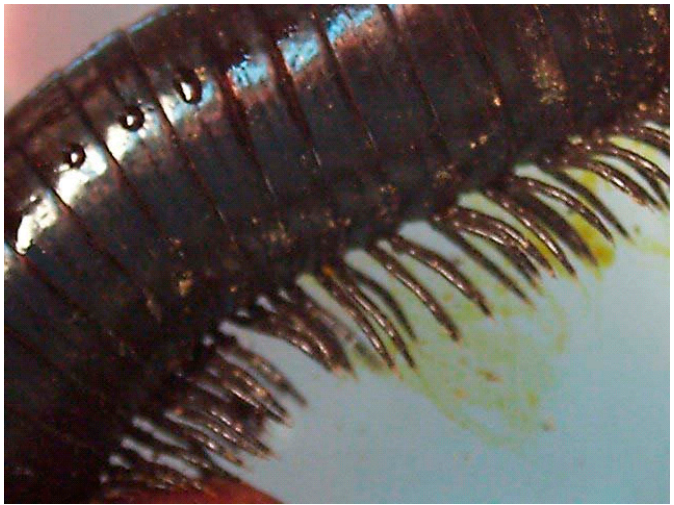

(b)

Figure 1. (a) droplets of secretion onto dorso-lateral surface of millipede's body ready for collecting via glass capillary; (b) collecting millipede defensive secretion via filter paper.

For the detection of antimicrobial activity, the defensive solution $(0.5-1000 \mu \mathrm{g} / \mathrm{mL})$ was placed in Petri dishes containing nutrient agar, aseptically adding the inoculum of the species of pathogenic microorganism to be analyzed in filter paper discs ( $4 \mathrm{~mm}$ diameter). The plates were incubated (72 h) at room temperature and the minimum inhibitory concentrations (MIC) were calculated. The general protocol is depicted in the Figure 2.

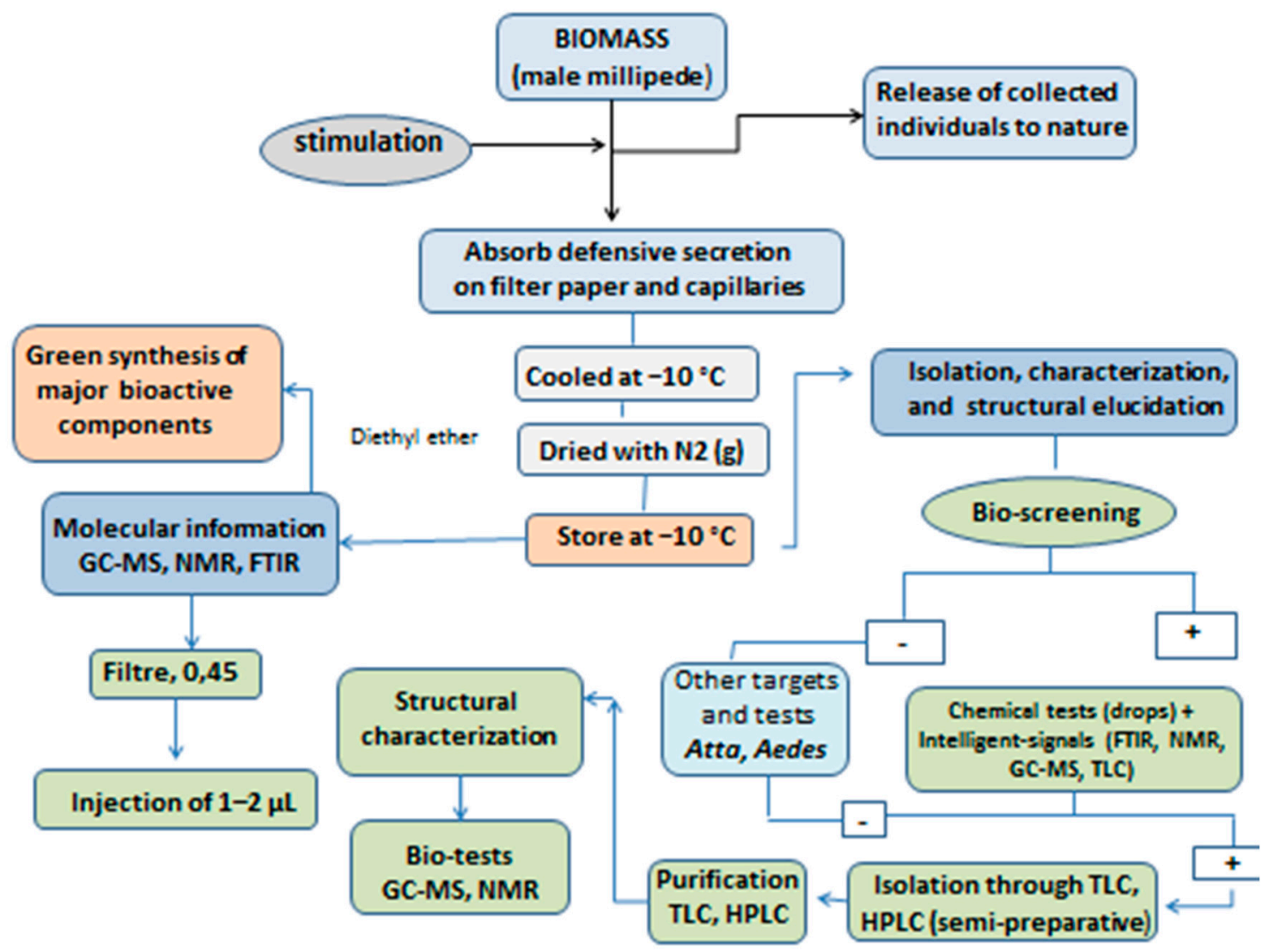

Figure 2. General protocol for studying defensive secretions isolated from Cuban endemic millipede gen. Rhinocricus sp., inhabiting in the western zone of the Cuban archipelago. 


\section{Results}

The analysis of the chemical composition of defensive secretions of terrestrial invertebrates facilitates the generation of a structural data of great significance for modeling and design studies not only of metabolic pathways, but also optimizes the synthesis of New Structural Entities and New Pharmacological Entities with potential application in various areas of human activity, increasing the added value of biodiversity as an eco-sustainable source of secondary metabolites. In this context, due to the absence of molecular information and structural knowledge about the chemical composition of the repugnatorial secretions of the Cuban endemic millipedes (gen. Rhinocricus sp.), it was decided to study, preliminary, these secretions collected from different population which inhabiting in the wester eco-geographical zone of the Cuban tropical archipelago.

The analysis, by thin layer chromatography (chromogenic reactions on $\mathrm{SiO}_{2}$ plates doped with oxalic acid and silver nitrate), of the repugnatorial secretions, collected in situ, of the populations under study of millipedes of the gen. Rhinocricus sp. revealed that all defensive secretions are polycomponent mixtures. The uses of specific reagents suggest the presence of quinonoid metabolites (phenols and benzoquinones) with a certain degree of substitution. (Figure 3).

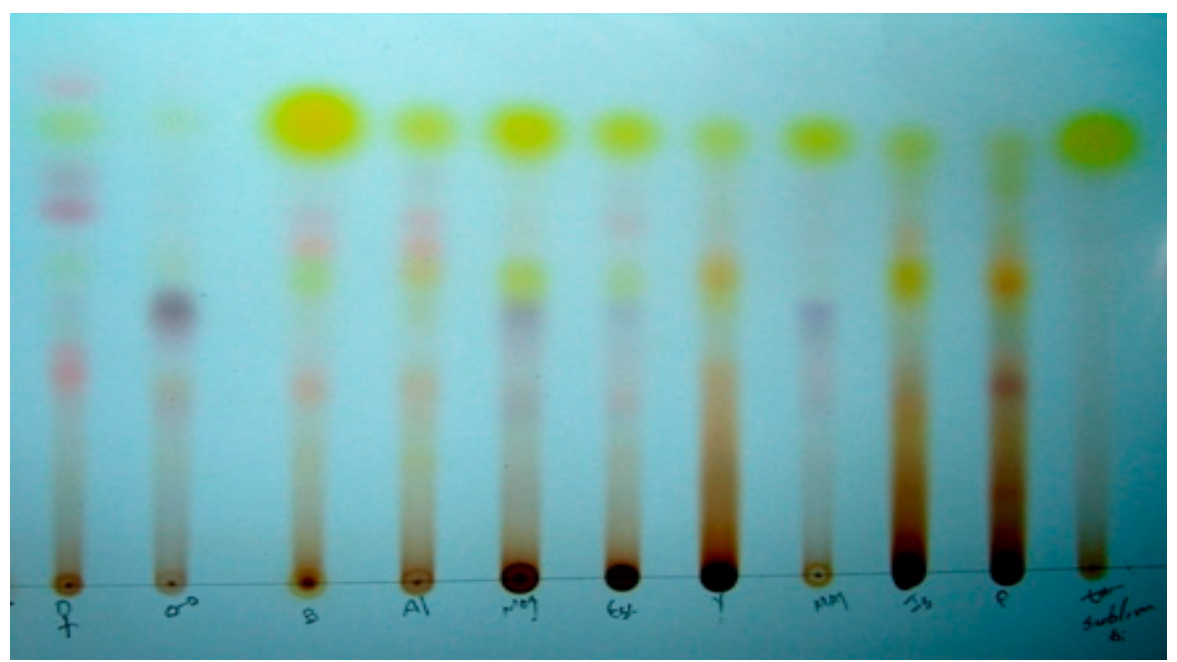

Figure 3. Thin Layer Chromatography (TLC) of the defensive secretions of millipede gen. Rhinocricus $\mathrm{sp}$, collected at the 6 collection sites of the study.

The compositional-structural analysis, by GC-MS and FTIR, of the millipede defensive secretions of the gen. Rhinocricus sp. that inhabits the western eco-geographical zone of the Cuban archipelago, collected in the six previously described sites revealed a great heterogeneity both in composition and in structural variations and molecular patterns.

The results of the GC-MS analysis are reported in Table 1.

The results of the in vitro bioassays to evaluate the microbiocidal action vs. pathogenic microorganisms of the defensive secretions are reported in Table 2.

Table 1. Secondary Metabolites detected in millipede defensive secretions from 6 populations under study of gen. Rhinocricus sp. inhabiting the Cuban archipelago.

\begin{tabular}{ccc}
$\begin{array}{c}\text { Collection } \\
\text { Site }\end{array}$ & $\begin{array}{c}\text { Retention Time (Rt, min.) and \% in the } \\
\text { Defensive Secretion }\end{array}$ \\
$\begin{array}{c}\text { Isla de la } \\
\text { Juventud }\end{array}$ & $\begin{array}{l}\text { 2-methylhydroquinone } \mathrm{Rt}=2,622 \text { min. }(38 \%) \\
\text { 3,4-dimethoxyphenol } \mathrm{Rt}=3,226 \text { min. }(61,8 \%)\end{array}$ \\
\hline
\end{tabular}




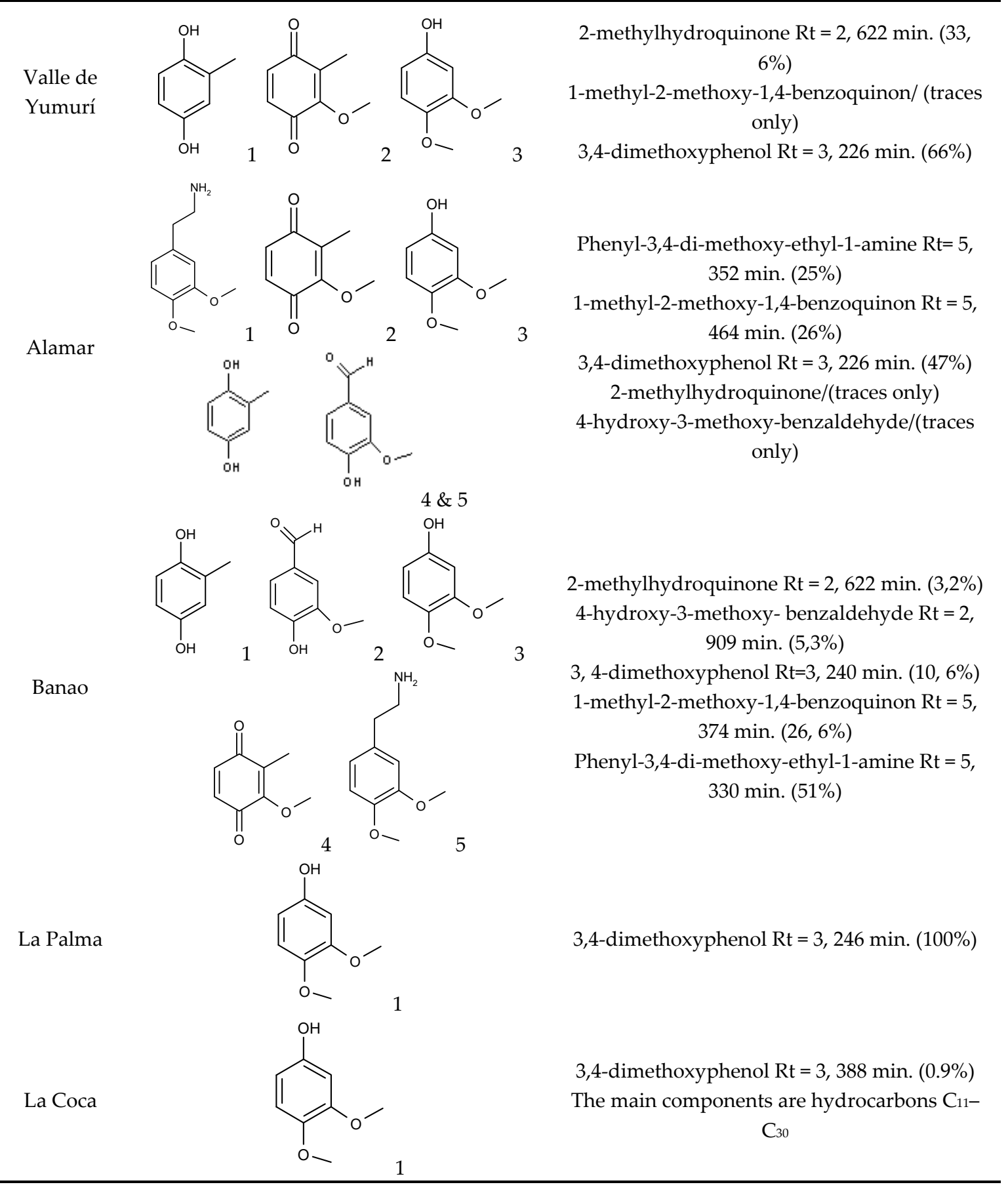

Table 2. Microbiocidal evaluation of defensive repugnatorial secretions from Rhinocricus sp. vs. pathogenic microorganisms.

\begin{tabular}{ll}
\hline Microorganism & $\begin{array}{l}\text { Toxicological Doses (MIC) } \\
\text { Minimal Inhibitory Concentrations }\end{array}$ \\
\hline Fonsecae pedrosi & MIC $=6.0 \mu \mathrm{g} / \mathrm{mL}$ \\
Candida albicans & $\mathrm{MIC}=30.0 \mu \mathrm{g} / \mathrm{mL}$ \\
Microsporum gypeseum & $\mathrm{MIC}=78.0 \mu \mathrm{g} / \mathrm{mL}$ \\
Microsporus canis & $\mathrm{MIC}=56.3 \mu \mathrm{g} / \mathrm{mL}$ \\
Trycophyton mentagraphytes & $\mathrm{MIC}=27.0 \mu \mathrm{g} / \mathrm{mL}$ \\
Epidermophyton flocossum & $\mathrm{MIC}=68.0 \mu \mathrm{g} / \mathrm{mL}$ \\
Trycophyton rubrum & $\mathrm{MIC}=44.0 \mu \mathrm{g} / \mathrm{mL}$ \\
\hline
\end{tabular}




\section{Discussion}

The taxonomic description of millipede species (endemic and regional) that inhabit the Cuban archipelago reveals the existence of approximately 75 species for central and eastern geographical areas of Cuba. In a preliminary approach, trying to apply, roughly, the concept of integrating, and structurally populating, the chemical space [4] of defensive secretions of endemic millipedes of the Rhinocricidae family and populations of endemic genus Rhinocricus sp., the possibility of studying metabolic profiles (chemical-compositional) of the defensive secretions of various populations of millipedes that inhabit the western part of Cuba was evaluated.

The theoretical basis on which we based our decision was:

- $\quad$ Endemic character of the described species (gen. Rhinocricus) and geographically differentiated populations (70-450 Km).

- Paleo-geological and phytogeographic patterns (native populations and their variations in the last 25-30 × $10^{6}$ years) that frame high endemism between botanical species and terrestrial invertebrates and considerations on structural singularity (chemistry) derived from the origins of invertebrate Cuban biota (continental connections).

- Possibility of correlating morphology-metabolism/secondary metabolite-eco-geographic patterns, in the search for specific chemo-types or biomarkers that facilitate the systematic classification of the species or sub-species of millipedes (including gen. Rhinocricus sp.).

- Applicability of secondary metabolites isolated and extracted from defensive secretions from millipedes gen. Rhinocricus such as NSE-NPE as molecular resource for advanced applied chemistry and its systemic integration to conservation strategies.

Based on the results described, a molecular distribution pattern of quinonoid molecular systems (substituted phenols and 1,4-benzoquinones) can be inferred. This is represented, as molecular mapping, in the Figure 4

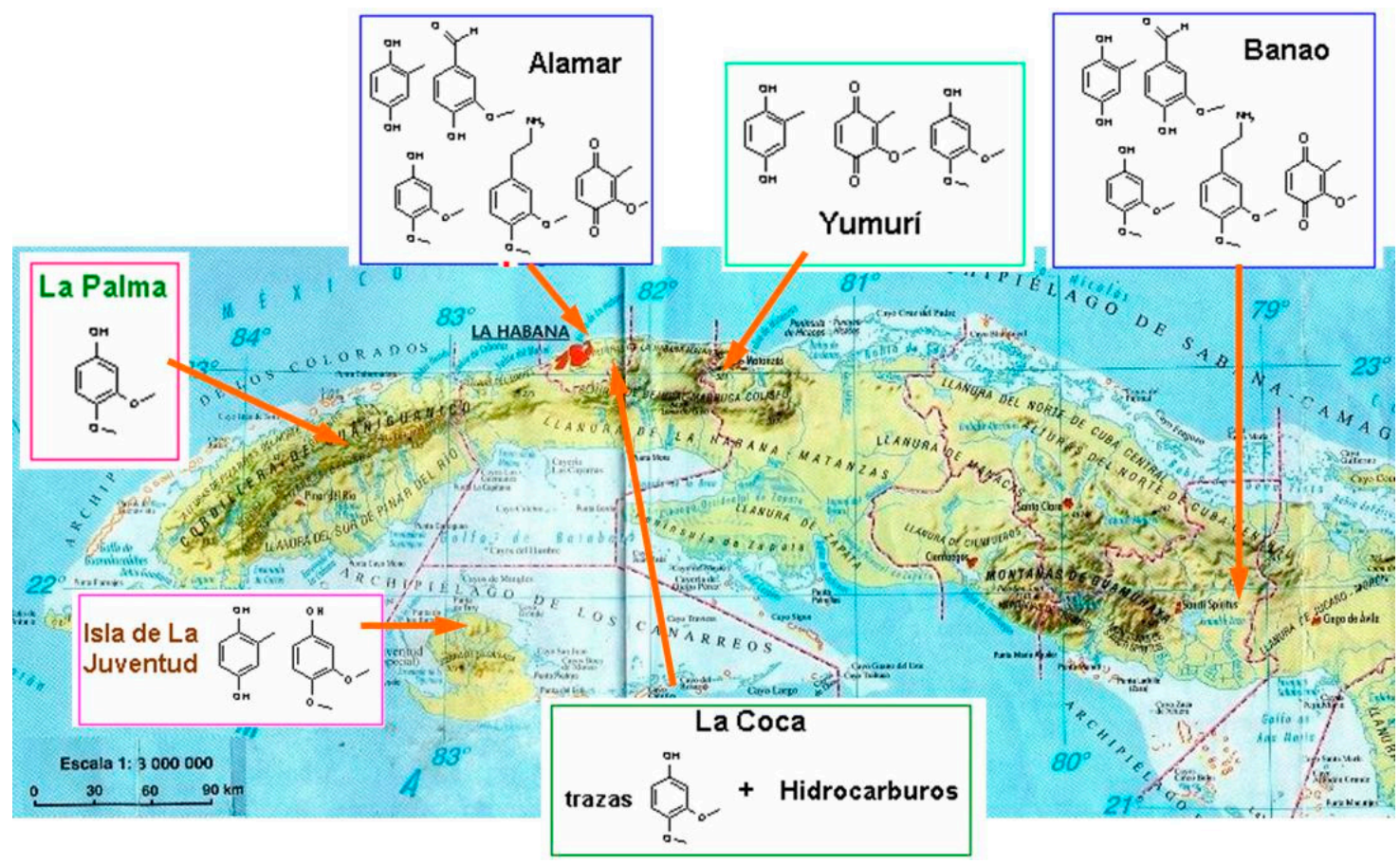

Figure 4. Molecular mapping of compositions of defensive secretions collected from millipedes gen. Rhinocricus sp., inhabiting in the wester zone of Cuban archipelago.

In our study, a great variability and heterogeneity have been observed in the substances that constitute the defensive secretions of the millipedes gen. Rhinocricus sp. in the populations under study (intra-specific variation). According to [5-7], there may be variations, both inter-specific and intra-specific, depending on sex, age, stage of biological development, climatic season, population or 
the evolution of the secretion mechanism, in addition to the diet of individuals, which adds even greater variability to the chemistry of secondary metabolites of repugnatorial secretions [8]. Also, within the same family or class if there is any degree of geographic isolation, variations in the chemical composition of their secretions are favored with respect to the major components because the predators (invertebrates and vertebrates) are not the same, nor their ecological pressure, in two geographically distant areas [9].

The insular conditions of Cuba favor evolutionary processes of rapid differentiation at the molecular level (concentrational variations of major components and oxidative enzymatic systems at the mitochondrial level) that take place in short periods of time in small eco-geographical spaces. The study of the geographic distribution patterns and variations of the compositions in the repugnatorial secretions of Diplopoda (gen. Rhinocricus sp.) reveals tendencies of the intra-species chemical microevolution and its dependencies vs. ecological, biotic and edafo-climatic parameters.

The mapping (molecular spacial distribution) of the obtained results reveals a significant geographical heterogeneity of the chemotypes observed in the defensive secretions of millipedes in the western area of the Cuban archipelago and the major components identified and quantified for each population of the Rhinocricus species.

\section{Conclusions}

It was evidenced the existence of eco-geographical variations and potential chemotypes in 6 populations of millipede gen. Rhinocricus sp. that inhabit in Cuban tropical archipelago (West ecogeographical region) The five chemotypes determined were: Yumurí Valley-Isla de la Juventud (two components 33,6 and 66\% respectively); Alamar-Banao collection sites (5-9 components with remarkable differences in secondary metabolite concentrations); La Palma (1 component, 100\%, phenolic nature); Coca (mixture of aliphatic hydrocarbons with traces of substituted phenols); and Yumurí Valley (quinona $>90 \%$ ). Two new molecular entities for defensive secretion of endemic Spirobolida gen. Rhinocricus sp. in Cuban tropical archipelago (Banao and Alamar collection area) were determined: 2-(3,4-dimethoxy-phenyl)-ethylene-1-amine and 4-hydroxy-5-methoxybenzaldehyde (vanillin). The molecular mapping of compositions of the defensive secretions isolated from Rhinocricus sp. populations revealed the existence of a singular compositional heterogeneity (aromatic, benzoquinone and hydrocarbon nature components with specific substitution patterns) in the western area of the Cuban archipelago. Repugnatorial secretions showed interesting microbiocidal activity vs. pathogenic micro-organisms $[10,11]$. Studies on the evolutionary and chemical significance of these poly-component mixtures are currently under development.

Author Contributions: Individual contributions is as follow: J.E.T.M. conceptualization and methodology, funding acquisition investigation and spectral data analysis; M.T.C.P. writing and preparation, review and editing.

Funding: This research received no government, academic or external funding.

Acknowledgments: This study was supported, in part, by the institutional support from Prometheus Project Ecuador "Chemical Bioprospecting of Tropical Biodiversity" 2016-2017.

Conflicts of Interest: The authors declare no conflict of interest.

\section{References}

1. Tacoronte, J.; Tchervas, T.; Prieto, D.; Rodriguez, C.; Aspiazu, M.; Gonzalez, V. A natural benzoquinone isolated from defensive secretions of Cuban endemic millipede. Rev. CNIC. Cienc. Quím. (Chem. Sci.) 2005, $36,115-116$.

2. Tacoronte, J.; Cabrera Pedroso, M.T. Defensive secretions of terrestrial invertebrates. Applied Chemical ecology. A molecular and ecosustainable perspective of the Ecuadorian biodiversity. In Un Espacio para la Ciencia; Manglar: Quito, Ecuador, 2018; Volume 1, Chapter 2, pp. 51-100.

3. Mesa, J.A.; Tacoronte, J.; Montes de Oca, R.; Tobellas y J.; Garrido, R. First report of 3,4-dimethoxyphenol, in defensive secretions of Cuban endemic millipedes (Spirobolida, Rhinocricidae, Rhinocricus). A study case Rhinocricus duvernoyi Karch 1881, geographical population of La Palma. Rev. CENIC Cienc. Quim. (Chem. Sci.) 2009, 40, 32-35. 
4. Waldmann, H.; Ertl, P.; Roggo, S.; Schuffenhauer, A.; Wetzel, S. Cheminformatic Analysis of Natural Products and their Chemical Space. Chimia 2007, 61, 355-360. doi:10.2533/chimia.2007.355.

5. Williams, L.; Singh, P. Biology and Biological Action of the Defensive Secretions from a Jamaican Millipede. Naturwissenschaften 1997, 84, 143-144.

6. Dossey, A. Insects and their chemical weaponry: New potential for drug discovery. Nat. Prod. Rep. 2010, 27, 1737-1757.

7. Taira, J.; Nakamura, K.; Higa, Y. The identfication of secretory compounds from the millipede Oxidus gracilis C. L. Koch (Polydesmida: Paradoxosomatidae) and their variation in different habitats. Appl. Entomol. Zool. 2003, 38, 401-404.

8. Shear, W. The chemical defenses of millipedes (diplopoda): Biochemistry, physiology and ecology. Biochem. Syst. Ecol. 2015, 61, 78-117.

9. Deml, R.; Huth, A. Benzoquinones and Hydroquinones in Defensive Secretions of Tropical Millipedes. Naturwissenschaften 2000, 87, 80-82.

10. Billah, M.K.; Kwang, D.; Adofo, C.; Olu-Taiwo, M.O.; Pesewu, G.A. Antibacterial activities of Millipedes extracts against selected bacterial pathogens. J. Microbiol. Antimicrob. Agents 2015, 1, 30-35.

11. Roncadori, W.; Duffey, S.; Blum, M. Antifungal activity of defensive secretions of certain millipedes. Mycology 1985, 72, 185-191.

(C) 2019 by the authors. Licensee MDPI, Basel, Switzerland. This article is an open access article distributed under the terms and conditions of the Creative Commons Attribution (CC BY) license (http://creativecommons.org/licenses/by/4.0/). 